\title{
Lack of Specific Involvement of (+)-Naloxone and (+)-Naltrexone on the Reinforcing and Neurochemical Effects of Cocaine and Opioids
}

\author{
Gianluigi Tanda*,', Maddalena Mereu', Takato Hiranita ${ }^{2}$, Juliana C Quarterman', Mark Coggiano' and \\ Jonathan L Katz ${ }^{2}$ \\ 'Medication Development Program, Molecular Targets and Medication Discovery Branch, NIDA-IRP, NIHIDHHS, Baltimore, MD, USA; \\ ${ }^{2}$ Psychobiology Section, Molecular Neuropsychiatry Research Branch, NIDA-IRP, NIHIDHHS, Baltimore, MD, USA
}

\begin{abstract}
Effective medications for drug abuse remain a largely unmet goal in biomedical science. Recently, the $(+)$-enantiomers of naloxone and naltrexone, TLR4 antagonists, have been reported to attenuate preclinical indicators of both opioid and stimulant abuse. To further examine the potential of these compounds as drug-abuse treatments, we extended the previous assessments to include a wider range of doses and procedures. We report the assessment of (+)-naloxone and (+)-naltrexone on the acute dopaminergic effects of cocaine and heroin determined by in vivo microdialysis, on the reinforcing effects of cocaine and the opioid agonist, remifentanil, tested under intravenous self-administration procedures, as well as the subjective effects of cocaine determined by discriminative-stimulus effects in rats. Pretreatments with $(+)$-naloxone or (+)-naltrexone did not attenuate, and under certain conditions enhanced the stimulation of dopamine levels produced by cocaine or heroin in the nucleus accumbens shell. Furthermore, although an attenuation of either cocaine or remifentanil self-administration was obtained at the highest doses of (+)-naloxone and (+)-naltrexone, those doses also attenuated rates of food-maintained behaviors, indicating a lack of selectivity of TLR4 antagonist effects for behaviors reinforced with drug injections. Drugdiscrimination studies failed to demonstrate a significant interaction of (+)-naloxone with subjective effects of cocaine. The present studies demonstrate that under a wide range of doses and experimental conditions, the TLR4 antagonists, (+)-naloxone and (+)-naltrexone, did not specifically block neurochemical or behavioral abuse-related effects of cocaine or opioid agonists.

Neuropsychopharmacology (2016) 4I, 2772-278I; doi:I0.1038/npp.2016.91; published online 6 July 2016
\end{abstract}

\section{INTRODUCTION}

Glia express the Toll-like receptor 4 (TLR4), a pattern recognition receptor that in the central nervous system reacts to potential toxic insults, triggering the release of proinflammatory and neuro-excitatory mediators (see Lee et al (2012) for review). Recent studies suggest that morphine can activate glia inflammatory responses by binding to TLR4 through an accessory protein, myeloid differentiation protein 2 (Hutchinson et al, 2010), an effect that may explain some opioid actions (Watkins et al, 2009). Interestingly, (+)-naloxone and (+)-naltrexone, inactive enantiomers of the corresponding (-)-opioid receptor antagonists (Iijima et al, 1978), have been found to dock to TLR4 using 'in silico' models, and have antagonist effects at this site in vitro and in vivo (Hutchinson et al, 2008; Lewis et al, 2012). Recently, these compounds were shown to blunt the tolerance and

* Correspondence: Dr G Tanda, Medication Development Program, TRIAD Building, NIDA Suite 330 I, 333 Cassell Drive, Baltimore, MD 21 224, USA, Tel: + I-443-740-2580, Fax: + |-443-740-2 I I I,

E-mail: Gtanda@mail.nih.gov

Received 21 December 20 15; revised 27 May 2016; accepted 30 May 2016; accepted article preview online 14 June 2016 dependence that develops to opioid agonists, as well as the self-administration of opioid agonists and cocaine (Hutchinson et al, 2012; Northcutt et al, 2015). Further, place conditioning and elevations in dopamine (DA) levels in the nucleus accumbens shell (NAS) produced by opioids and cocaine were reported to be blunted by $(+)$-naltrexone and (+)-naloxone (Hutchinson et al, 2012; Northcutt et al, 2015). Together, these findings suggest a role for TLR4 in drug abuse to both opioids and psychostimulants, as well as an approach to the development of treatments for substance abuse disorders (Bachtell et al, 2015).

The reinforcing effects of drugs abused by humans are believed to be mediated by several specific mechanisms that converge on activation of DA neuronal signaling from the ventral tegmental area (VTA) to the NAS (Di Chiara et al, 1993; Koob and Volkow, 2010). Opioids increase NAS DA levels by reducing the inhibitory control of VTA GABA neurons on DA neuronal firing that facilitates DA release from the NAS DA nerve terminals (Di Chiara and North, 1992; Johnson and North, 1992; Tanda et al, 1997a). Indirect DA agonists, such as cocaine and amphetamines, increase synaptic DA levels in the NAS by interacting with the DA transporter (DAT) at presynaptic DA nerve terminals 
(Pontieri et al, 1995; Tanda et al, 1997b). However, the studies by Hutchinson et al (2012) and Northcutt et al (2015) suggest that TLR4 antagonists inhibit opioid and cocaine reinforcement through an initial blockade of TLR4 receptors. Thus, they have hypothesized that TLR4 signaling induced by drugs of abuse from the very first administration may produce reinforcing actions, possibly through the same dopaminergic VTA-NAS neuronal pathways, but by a neuroinflammatory response (Hutchinson and Watkins, 2014). These findings suggest a novel mechanism of action shared among different classes of abused drugs that is distinct from the well-studied dopaminergic mechanisms (Di Chiara et al, 1999; Di Chiara et al, 1998; Wise, 1998).

The importance of the TLR4 hypothesis is amplified by the lack of effective therapies for substance use disorders and their substantial societal and medical consequences. However, there are several other findings that may temper the promise of reported interactions among TLR4 antagonists and abused drugs. In particular, recent studies have not confirmed involvement of TLR4 in morphine-induced tolerance or dependence (Fukagawa et al, 2013; Skolnick et al, 2014; Stevens et al, 2013) or the attenuation of tolerance produced by the microglial inhibition (Fukagawa et al, 2013). Further, a recent paper (Mattioli et al, 2014) demonstrated with in vivo studies that morphine-induced tolerance, hyperalgesia, and physiological dependence was retained in TLR4 genetically modified null mice. Other studies have shown that opioids, including morphine at low concentrations potentiate, whereas higher concentrations inhibit, lipopolysaccharide-induced activation of NF- $\kappa \mathrm{B}$, a protein controlling cytokine production and expression (Roy et al, 1998). Inhibition of NF- $\kappa$ B activation produced by morphine or fentanyl was not blocked by opioid antagonists, naloxone or $\beta$-FNA, which themselves noncompetitively inhibited NF- $\kappa \mathrm{B}$ activation (Stevens et al, 2013).

On the basis of the published findings about TLR4 involvement in substance use disorders (Hutchinson et al, 2012; Northcutt et al, 2015), the present study further examined the influence of $(+)$-naloxone and (+)-naltrexone, TLR4 antagonists on several effects of cocaine and opioids directly related to their abuse under a variety of procedures. Given the different, but convergent, acute mechanisms of action of stimulants and opioids on NAS DA (Pontieri et al, 1995; Tanda et al, 1997a; 1997b), the present study assessed and extended the effects of different doses of $(+)$-naltrexone and (+)-naloxone, on acute dopaminergic responses to heroin and cocaine as an index of DA neurotransmission (Di Chiara et al, 1996). Microdialysis experiments were conducted under several different experimental conditions. In addition, the effects of (+)-naloxone and (+)-naltrexone were assessed on the self-administration of the opioid agonist, remifentanil, or cocaine. Finally, the effects of (+)-naloxone were assessed on the subjective effects of cocaine assessed by drugdiscrimination procedures without the need for surgical preparation as surgical operations could potentially trigger TLR4-mediated inflammatory responses.

\section{MATERIALS AND METHODS}

The online Supplementary Information includes a version of the methods which should be consulted for all details. The following is an abbreviated description.

\section{Subjects}

All subjects in these studies were experimentally-naive male Sprague-Dawley rats (Taconic Farms, Germantown, NY, or Charles River, Wilmington, MA), 275-350 g.

\section{Compounds}

The following drugs were used: (+)-naloxone $\mathrm{HCl}$ and (+)-naltrexone $\mathrm{HCl} .2 \mathrm{H}_{2} \mathrm{O}$ (stereochemically pure synthesized and kindly donated by Dr Kenner Rice, NIDA IRP, Drug Design and Synthesis Section; Iijima et al, 1978). These compounds were identical to those used previously (Hutchinson et al, 2012; Theberge et al, 2013; Northcutt et al, 2015). Other compounds used and their sources are provided in the Supplementary Information.

\section{In vivo Brain Microdialysis}

Probes had an active dialyzing surface of $1.8-2.0 \mathrm{~mm}$, and in experiments 1-4 rats were implanted during surgical procedures (uncorrected coordinates (Paxinos and Watson, 1998 ) in mm from bregma: anterior 2.0 , lateral \pm 1.0 , vertical 7.9 (from dura)) under a mixture of ketamine and xylazine anesthesia (60.0 and $12.0 \mathrm{mg} / \mathrm{kg}$, i.p., respectively), as described previously (Garces-Ramirez et al, 2011; Tanda et $a l, 2005 ; 2007)$. In experiment 4 a group of rats was implanted with probes under isoflurane anesthesia, and results were compared with those obtained with ketamine/ xylazine. For experiment 5, guide cannulas (BAS, Lafayette, IN) were used and unilaterally implanted at the following uncorrected coordinates (Paxinos and Watson, 1998) in $\mathrm{mm}$ from bregma: anterior 1.8, lateral \pm 1.0 , vertical 5.5 (from dura). These subjects recovered from 5 to 12 days (nominally 1 week) or 19 to 22 days (nominally 3 weeks) before the implant of the probe, which extended about $2.5 \mathrm{~mm}$ from the guide cannula, but with only $1.8-2 \mathrm{~mm}$ of dialyzing surface. These probes were almost identical to those used for experiments 1-4, but the stainless-steel shaft was mounted on the empty skeleton of a BAS microdialysis probe in order to perfectly fit with the BAS guide cannula. For experiments 1 and 2, a silastic catheter was implanted into the right external jugular vein during the same surgical procedure to allow intravenous (i.v.) injections (Garces-Ramirez et al, 2011; Tanda et al, 2008). Please note that in experiments 1 and 2, at $70 \mathrm{~min}$ after the first, a second identical dose of (+)-naltrexone was administered again to ensure continued elevated levels of the compound during assessments of the effects of the highest doses of heroin or cocaine.

Experiments were performed on freely moving rats in hemispherical CMA-120 cages (CMA/Microdialysis AB, Solna, Sweden), $\sim 22-24 \mathrm{~h}$ after probe implant. Dialysates were sampled every $10 \mathrm{~min}(1.0 \mu \mathrm{l} / \mathrm{min})$ and immediately analyzed. After reaching stable DA values (2-4 consecutive samples, $<10 \%$ variability), rats were treated with drugs. DA was detected in dialysate samples by HPLC coupled with a coulometric detector (Coulochem II or III, ESA, Chelmsford, MA), all chromatographic conditions are as reported previously (Tanda et al, 2009). Data were only used from subjects for which probe tracks were within the correct NAS boundaries (Pontieri et al, 1996; Tanda et al, 1997a; 1997b; see Supplementary Figure 1). 
Heroin i.v.

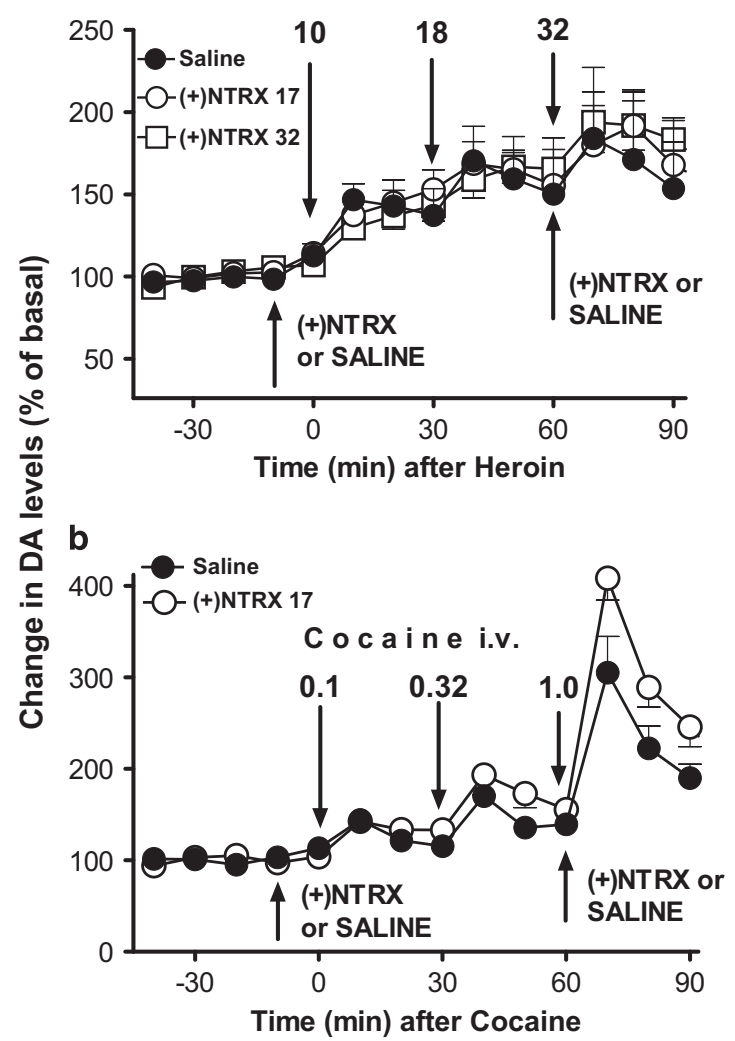

Figure I (a) Results from microdialysis experiment I, time course of heroin, 10, 18, and 32 micrograms $/ \mathrm{kg}$, i.v., injected $30 \mathrm{~min}$ apart, on DA levels in dialysates from the NAS, 10 min after pretreatments with (+)-naltrexone ((+) NTRX), 17 or $32 \mathrm{mg} / \mathrm{kg}$ or saline, s.c. Pretreatments were repeated at $60 \mathrm{~min}$ in order to avoid any potential fading of their pharmacological effects. Data are expressed as percentage of basal values \pm SEM. (b) Results for microdialysis experiment 2, time course of administration of cocaine, $0.10,0.32$, and $1.0 \mathrm{mg} / \mathrm{kg}$ i.v., injected $30 \mathrm{~min}$ apart, on DA levels in dialysates from the NAS, 10 min after pretreatments with NTRX, $17 \mathrm{mg} / \mathrm{kg}$ s.c., or saline. Pretreatments were repeated at $60 \mathrm{~min}$ in order to avoid any potential fading of (+)-naltrexone effects. Data are expressed as percentage of basal values \pm SEM.

Microdialysis results were expressed as a change in DA concentrations calculated as the percentage of basal DA values. One-way ANOVA was applied to evaluate potential differences in basal NAS DA values from different treatment groups. Two-, or three-way ANOVA, for repeated measures were applied to microdialysis results, using time, drug-dose, and $(+)$-opioid-pretreatment as factors, with significant results subjected to Tukey's post hoc test. In experiment 1 and 2, where three different doses of heroin or cocaine were administered $30 \mathrm{~min}$ apart from each other, drug-dose, time, and (+)-naltrexone pretreatment were used as factors in the three-way ANOVA.

\section{Behavioral Studies}

Experimental sessions were conducted daily with subjects placed in operant-conditioning chambers. Self-administration procedures used were the same as those used in Hutchinson et al (2012) and Northcutt et al (2015). Subjects were initially trained with food reinforcement to press the right lever, and were subsequently trained under a fixed ratio (FR) five-response schedule of reinforcement (each fifth response produced a food pellet). One group of subjects continued with food reinforcement $(n=12)$, whereas subjects in the other groups $(n=18)$ were surgically implanted (under ketamine/xylazine anesthesia) with chronic indwelling jugular vein catheters and after recovery trained to selfadminister cocaine. Both food and cocaine sessions were divided into five 20-min components, each proceeded by a 2 -min timeout (TO) period in which responding had no consequences. Different cocaine doses or food amounts were available in each component in order to assess their effects on response rates. In the first component neither drug nor food was unavailable (also referred to as extinction, or EXT, because responses had no scheduled consequences).

Response rates were determined by dividing responses by elapsed time in each component, excluding the TO periods that followed drug injections or food presentations (and their delivery times). Statistical analyses were carried out with one-, two-, or three-way ANOVA, using component (dose or food amount) and pretreatment as factors for repeated measures with significant results subjected to Bonferroni post hoc test.

During cocaine discrimination procedures, lever-press responses were intermittently reinforced (FR 20) only on one lever after cocaine $(10 \mathrm{mg} / \mathrm{kg}$ i.p.) and the other lever after saline injection. The percentage of cocaine lever responding was calculated by dividing the number of responses on the cocaine-associated lever by the number of responses on both levers. Rates of responding were calculated by dividing the total numbers of responses by time and are expressed as percentage of saline (control) rate of responding. These data are shown as mean values $( \pm$ SEM) for groups of five subjects at each drug dose.

\section{RESULTS}

\section{Neurochemistry}

No significant differences $(p>0.05)$ were found in basal NAS DA concentrations among experimental control and $(+)$-opioid treated groups (ANOVA, $\mathrm{F}_{13,67}=1.23, p=0.276$ ). Average basal DA values, $n=81$, in $10 \mu$ l dialysates collected in 10 min samples from probes implanted in the rat NAS (see Supplementary Figure 1) were $38.5 \pm 2.21$ fmoles \pm SEM.

In experiment 1 , heroin (10.0 to $32.0 \mu \mathrm{g} / \mathrm{kg}$, i.v.) produced a dose-related stimulation of DA levels in the NAS (Fig. 1a, filled symbols). No significant difference was found between saline and s.c. (+)-naltrexone pretreatments on heroininduced stimulation of DA. A 3-way ANOVA showed significant effects of heroin dose $\left(\mathrm{F}_{3,44}=9.73, p<0.001\right)$, and time by heroin dose $\left(\mathrm{F}_{6,88}=3.03, p<0.01\right)$, but nonsignificant effects of time, pretreatment, time by pretreatment, dose by pretreatment, and time by dose by pretreatment interactions. The post hoc tests showed significant $(p<0.05)$ increases in DA after heroin doses of 0.018 and $0.032 \mathrm{mg} / \mathrm{kg}$ compared with their respective basal values for all saline and $(+)$-naltrexone pretreated groups.

In experiment 2 , cocaine $(0.1-1.0 \mathrm{mg} / \mathrm{kg}$, i.v.) also produced a dose-related stimulation of DA levels in the NAS (Figure 1b, filled symbols). A significantly larger increase in NAS DA levels was obtained in the s.c. (+)-naltrexone pretreated group 
compared with controls, particularly at the $1.0 \mathrm{mg} / \mathrm{kg}$ dose of cocaine. A three-way ANOVA showed significant effects of cocaine dose, pretreatment, and time $\left(\mathrm{F}_{3,28}=84.63\right.$, $p<0.001 ; \mathrm{F}_{1,28}=11.15, \quad p<0.001 ; \mathrm{F}_{2,56}=40.91, \quad p<0.001$, respectively), as well as a trend toward significance in the cocaine dose by pretreatment interaction $\left(\mathrm{F}_{3,28}=2.404\right.$, $p=0.08)$. Significant interactions of time by dose, time by pretreatment, and time by cocaine dose by pretreatment were also obtained $\left(\mathrm{F}_{6,56}=19.34, p<0.001 ; \mathrm{F}_{2,56}=3.48, p<0.05\right.$; $\left.\mathrm{F}_{6,56}=2.565, p<0.05\right)$. A statistical analysis of $(+)$-naltrexone pretreatment on cocaine $(1.0 \mathrm{mg} / \mathrm{kg}$ i.v.) showed a significant change in DA levels as compared with saline pretreatment (two-way ANOVA, significant main effects of pretreatment, $\mathrm{F}_{1,7}=9.26, p<0.02$, and time $\mathrm{F}_{2,14}=21.19, p<0.001 ;$ no significant time by pretreatment interaction $\mathrm{F}_{2,140 .}=5.38$, $p<0.001)$.

In experiment 3, cocaine administered i.p. (10 and $20 \mathrm{mg} / \mathrm{kg}$ ) also dose-dependently and significantly stimulated DA levels in dialysates from the NAS (Fig. 2 A, B). A twoway ANOVA showed significant effects of cocaine dose, time, and the time by dose interaction $\left(\mathrm{F}_{1,14}=46.86\right.$, $p<0.001 ; \quad F_{9,126}=21.21, p<0.001 ; F_{9,126}=5.38, p<0.001$, respectively). Pretreatment with (+)-naltrexone $(17 \mathrm{mg} / \mathrm{kg}$, s.c.) did not significantly modify the dopaminergic effects of cocaine $10 \mathrm{mg} / \mathrm{kg}$ (i.p.), though there was a trend toward a greater cocaine-induced stimulation of DA compared with saline (Fig. 2a). A two-way ANOVA showed a significant effect of time $\left(\mathrm{F}_{9,126}=14.82, p<0.001\right)$, though neither significant effects of (+)-naltrexone pretreatment (NS) nor the pretreatment by time interaction (NS). Pretreatments with (+)-naltrexone (17 and $32 \mathrm{mg} / \mathrm{kg}$ s.c.) were similarly ineffective in modifying the dopaminergic effects of cocaine at $20 \mathrm{mg} / \mathrm{kg}$ (i.p.), though there was a trend toward an enhancement of cocaine effects after the $32 \mathrm{mg} / \mathrm{kg}$ dose of naltrexone (Figure 2B). A two-way ANOVA showed a significant effect of time $\left(\mathrm{F}_{9,180}=42.00, p<0.001\right)$ and nonsignificant effects of pretreatment (NS) and pretreatment by time interaction (NS).

Anesthetic agents, in experiment 4, did not alter the effects of cocaine on DA levels (Figure 2C). However, when animals were pretreated with $(+)$-naloxone $(2 \times 2.5 \mathrm{mg} / \mathrm{kg}$, s.c., $10 \mathrm{~min}$ apart) before $10 \mathrm{mg} / \mathrm{kg}$ i.p. cocaine (the treatment regimen reported effective by Northcutt et al, 2015), a greater stimulation of DA levels was found compared with saline controls (Figure 2C). A two-way ANOVA indicated significant effects of (+)-naloxonepretreatment $\left(\mathrm{F}_{2,10}=5.19, p<0.05\right)$, and time $\left(\mathrm{F}_{2,20}=3.81\right.$, $p<0.05)$, but not significant time by $(+)$-naloxone-pretreatment interaction $\left(\mathrm{F}_{4,20}=0.26, \mathrm{NS}\right)$.

Implanting guide cannulas 1 or 3 weeks before the microdialysis assessments, as in experiment 5, did not significantly alter the DA response to $10 \mathrm{mg} / \mathrm{kg}$ cocaine compared with that obtained when probes were implanted without guide cannulas the day before (Figure 2d). In addition, this surgical procedure did not render effects of $(+)$-naloxone $(2 \times 2.5 \mathrm{mg} / \mathrm{kg}$, s.c. $)$ pretreatment significantly different from vehicle controls. However, there was a significantly longer lasting cocaine-induced increase in DA levels after (+)-naloxone compared with saline pretreatment (Figure 2D). A three-way ANOVA indicated non-significant effects of 1- or 3-week cannula-surgery group $\left(\mathrm{F}_{1,15}=1.31\right.$, NS), and pretreatment $\left(\mathrm{F}_{1,15}=0.91\right.$, NS); however, significant effects of time-course $\left(\mathrm{F}_{9,135}=41.46, p<0.01\right)$, time by cannula surgery-time group interactions $\left(\mathrm{F}_{9,135}=2.77, p<0.01\right)$ and time by $(+)$-naloxone-pretreatment interaction $\left(\mathrm{F}_{9,135}=2.70\right.$, $p<0.01)$ were obtained. Finally, non-significant effects of cannula surgery-time-group by $(+)$-naloxone-pretreatment interaction (NS) as well as the interaction of time, cannula surgery-time-group, and (+)-naloxone-pretreatment (NS) were obtained.

\section{Behavioral Studies}

Cocaine maintained rates of responding at 0.10 and $0.32 \mathrm{mg} /$ $\mathrm{kg} /$ inj that were significantly greater than those obtained with saline in the corresponding components of the session (Figure 3a). None of the opioid antagonists or their (+)-enantiomers maintained rates of responding substantially above those maintained by vehicle (Supplementary Figure 2). The cocaine self-administration dose-effect curve was not altered by most doses of $(-)$-naltrexone (Figure $3 b$ ) or (+)-naloxone (Figure 3c). Two-way ANOVA indicated significant effects of (+)-naloxone pretreatment dose (ANOVA, $\mathrm{F}_{5,100}=7.47, p<0.001$ ), cocaine dose (ANOVA, $\mathrm{F}_{4,100}=6.33, p=0.002$ ), and their interaction (ANOVA, $\left.\mathrm{F}_{20,100}=3.86, p<0.001\right)$. Post hoc tests indicated that the highest dose of (+)-naloxone $(56 \mathrm{mg} / \mathrm{kg})$ significantly decreased rates of responding maintained by cocaine at $0.010(t=4.96, \mathrm{p}<0.001), 0.032(t=7.54, \mathrm{p}<0.001)$ and 1.0 $(t=3.07, \quad \mathrm{p}=0.015) \mathrm{mg} / \mathrm{kg}$ (Figure 3C). In addition, pretreatment with increasing doses of $(+)$-naltrexone produced dose-related decreases in the maximal self-administration of cocaine (Figure 3D). Two-way ANOVA indicated significant effects of (+)-naltrexone pretreatment dose (ANOVA, $\mathrm{F}_{5,100}=5.73, p=0.001$ ), cocaine dose (ANOVA, $\mathrm{F}_{4,100}=8.55, p<0.001$ ), and their interaction (ANOVA, $\quad \mathrm{F}_{20,100}=4.65, \quad p<0.001$ ). These decreases were significant (as indicated by post hoc tests) at 32 $(t=5.81, p<0.001)$ and $56(t=4.98, p<0.001) \mathrm{mg} / \mathrm{kg}$ of $(+)$-naltrexone.

The opioid agonist, remifentanil, when substituted for cocaine, maintained response rates with an inverted U-shaped function of dose (Figure 3e, filled symbols), which were greater than those obtained with saline at doses above $0.1 \mu \mathrm{g} / \mathrm{kg} / \mathrm{inj}$ (compare filled symbols, Figure 3e, with open circles in Figure 3a).

The opioid antagonist ( - )-naloxone (s.c.) dose-dependently shifted the remifentanil self-administration dose-effect curve to the right (Figure $3 \mathrm{e})$. The lowest dose $(0.01 \mathrm{mg} / \mathrm{kg})$ was without effects while the three- and ten-fold higher doses shifted the remifentanil dose-effect curve to the right. The highest dose $(0.32 \mathrm{mg} / \mathrm{kg})$ produced an antagonism that was insurmountable over the range of remifentanil doses examined. A similar dose-dependent antagonism of remifentanil self-administration was produced by ( - )-naltrexone (Figure 3f).

Showing expected opioid-receptor stereospecificity, (+)-naloxone (s.c.) was without effects on remifentanil selfadministration up to $32 \mathrm{mg} / \mathrm{kg}$ (Figure $3 \mathrm{~g}$ ), a dose 1000 -fold greater than the minimally effective dose of its (-)-enantiomer. At $56 \mathrm{mg} / \mathrm{kg}(+)$-naloxone significantly decreased maximal remifentanil self-administration. Post hoc tests indicated significant decreases at remifentanil doses of 0.32 , 1.0 , and $3.2 \mu \mathrm{g} / \mathrm{kg} / \mathrm{inj}$. Similarly, pretreatments with increasing doses of $(+)$-naltrexone (s.c.) produced dose-related 

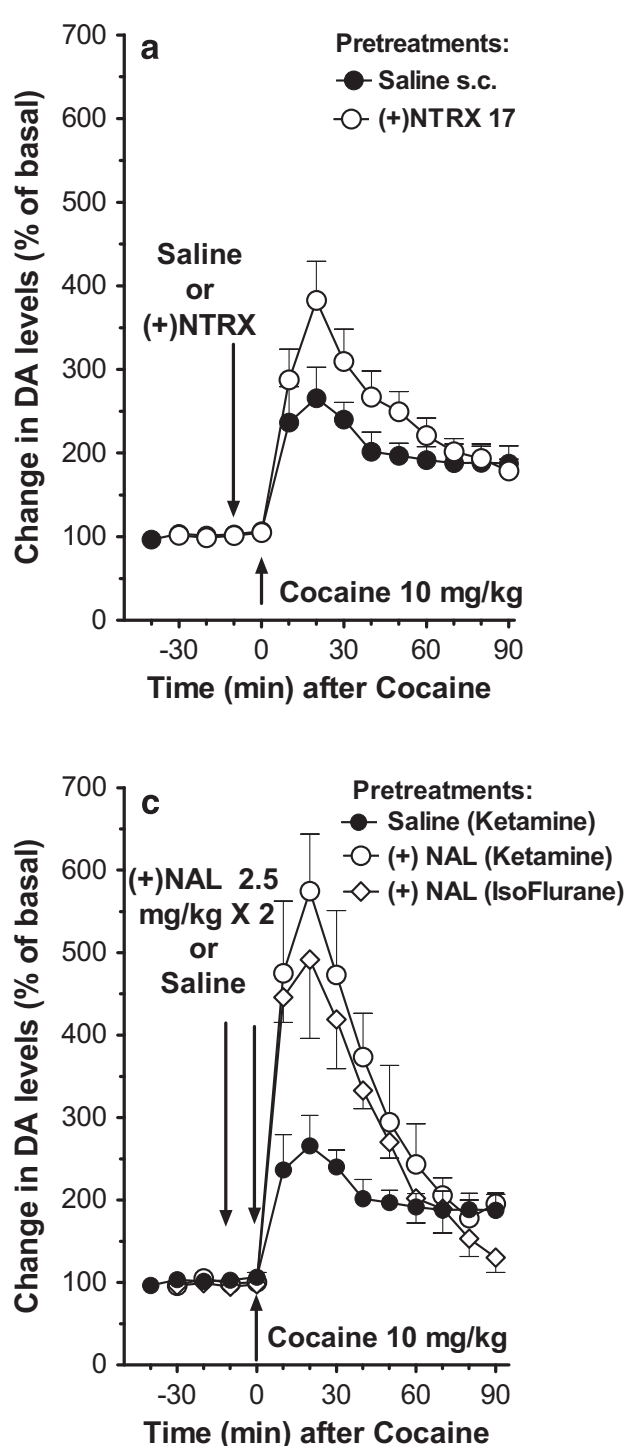
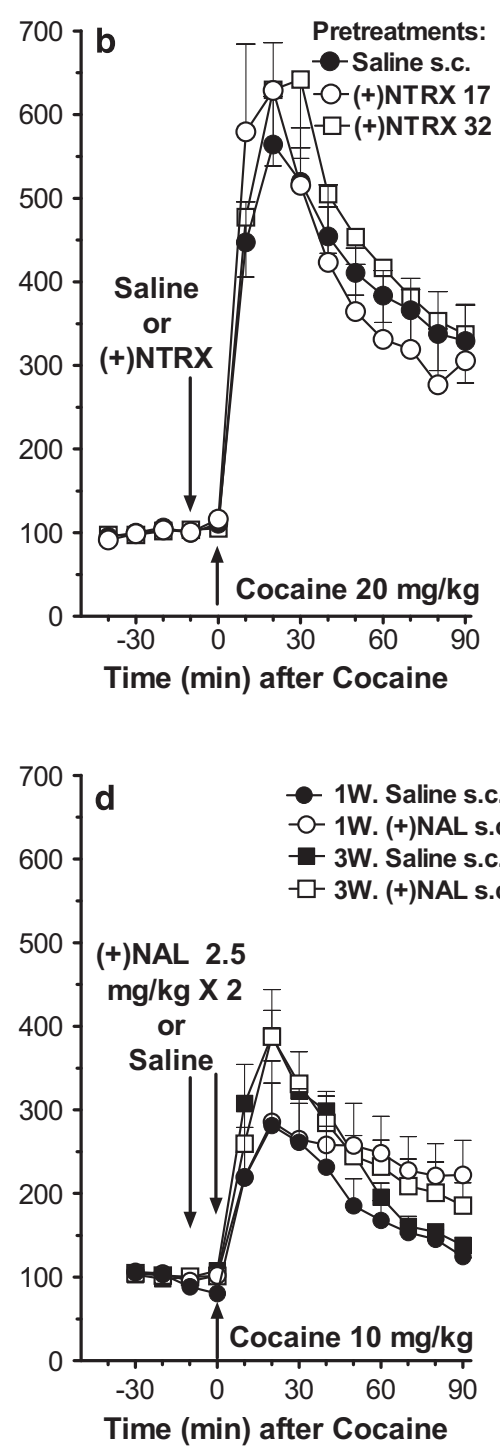

Figure 2 (a, b) Results from microdialysis experiment 3, time course of cocaine 10 (a) or 20 (b) mg/kg i.p., on DA levels in dialysates from the NAS, I0 min after pretreatments with (+)-naltrexone (NTRX), 17-32 mg/kg or saline, s.c. Data are expressed as percentage of basal values \pm SEM. Pretreatment (s.c.) with $(+)$-naltrexone $(17 \mathrm{mg} / \mathrm{kg})$ did not significantly modify the dopaminergic effects of cocaine $10 \mathrm{mg} / \mathrm{kg}$, i.p., though there was a trend toward a greater increase in dopamine levels as compared with that obtained after saline pretreatment (a). Pretreatments (s.c.) with (+)-naltrexone (I7 and $32 \mathrm{mg} / \mathrm{kg})$ were similarly ineffective in modifying the dopaminergic effects of $20 \mathrm{mg} / \mathrm{kg}$ (i.p.) of cocaine, with a trend toward an enhancement of effects at the higher dose (b). (c) Results from microdialysis experiment 4, time course of cocaine $10 \mathrm{mg} / \mathrm{kg}$ i.p., on DA levels in dialysates from the NAS, 10 min after pretreatments with (+)-naloxone (NAL), $2.5 \mathrm{mg} / \mathrm{kg}$ or saline, s.c., which was also administered again at the same time with cocaine administration, as conducted by Northcutt et al (20 I5). In this experiment we used different groups of rats surgically implanted with probes under ketamine or isoflurane anesthesia. Data are expressed as percentage of basal values \pm SEM. Regardless of surgical anesthetic used, a significantly greater stimulation of DA levels was found in rats pretreated with NAL compared with control rats pretreated with saline before cocaine. (d) Results for microdialysis experiment 5, time course of cocaine 10 mg $/ \mathrm{kg}$ i.p., on DA levels in dialysates from the NAS, 10 min after pretreatments with saline or NAL, $2.5 \mathrm{mg} / \mathrm{kg}$, s.c., which was also administered again at the same time with cocaine administration, as conducted by Northcutt et al (20I5). In this experiment we used different groups of rats surgically implanted with guide cannulas 5-12 days (IW) or I9$2 \mathrm{I}$ days $(3 \mathrm{~W}$ ) before the implant of the microdialysis probes. Data are expressed as percentage of basal values \pm SEM.

decreases in the maximal self-administration of remifentanil (Figure 3H). Two-way ANOVA indicated significant effects of remifentanil dose (ANOVA, $\mathrm{F}_{4,100}=6.19, p=0.002$ ), significant effects of (+)-naltrexone pretreatment dose (ANOVA, $F_{5,100}=3.18, p=0.023$ ), and their interaction (ANOVA, $\mathrm{F}_{20,100}=2.96, p<0.001$ ). Post hoc tests indicated that both $32(t=3.33, p=0.007)$ and $56(t=4.55, p<0.001)$ $\mathrm{mg} / \mathrm{kg}$, significantly decreased the maximal self-administration of remifentanil.
The TLR4 antagonists (+)-naloxone and (+)-naltrexone produced dose-related decreases in food-maintained responding (Figure 4, filled symbols, and also Supplementary Figure 3), which were significant at the highest doses. The potencies for decreasing food-maintained responding (Figure 4, circles) were not different from the potencies of these drugs to decrease the maximal rates of responding maintained by remifentanil (Figure 4, triangles up) or cocaine injections (Figure 4, triangles down). 
a

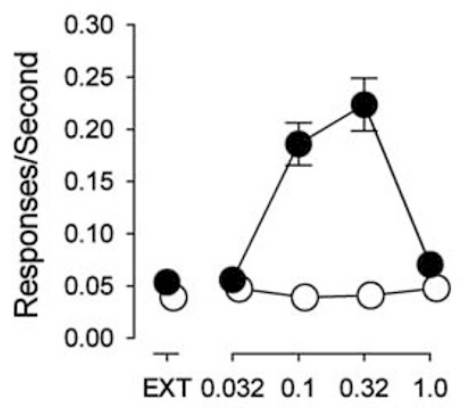

\begin{tabular}{lllll}
\hline & 2 & 3 & 4 & 5
\end{tabular}

Component (saline, i.v.)

$$
\text { b } \oplus 32 \mathrm{mg} / \mathrm{kg}
$$

(-)-Naltrexone (s.c.)

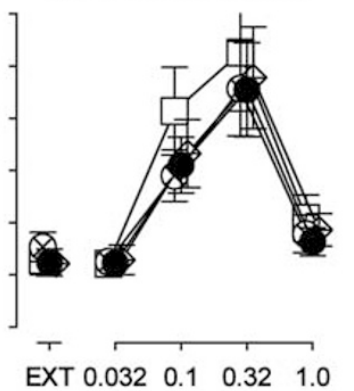

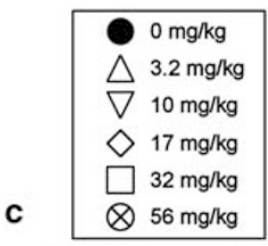

(+)-Naloxone (s.c.)

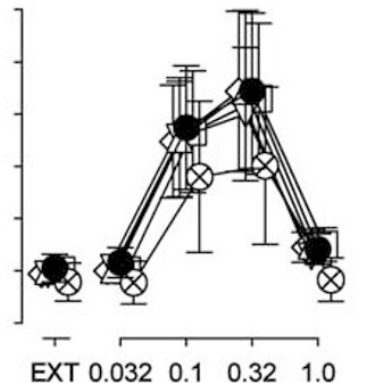

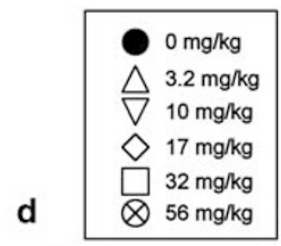

(+)-Naltrexone (s.c.)

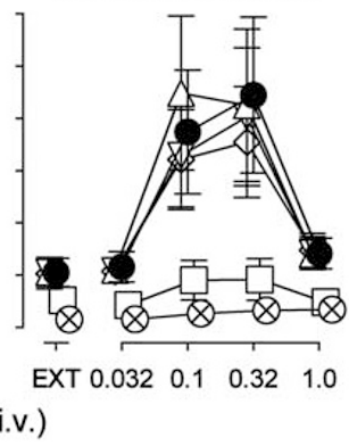

Cocaine Dose (mg/kg/injection, i.v.)

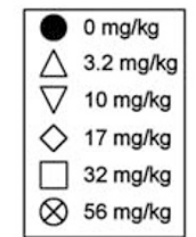

(+)-Naloxone (s.c.)

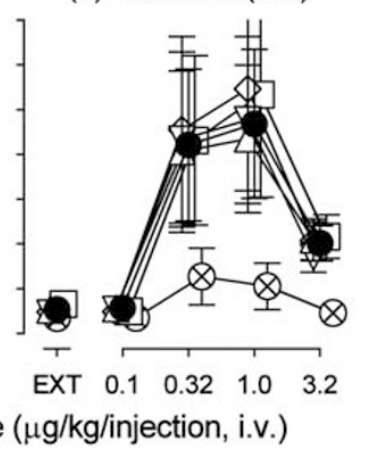

(+)-Naltrexone (s.c.)
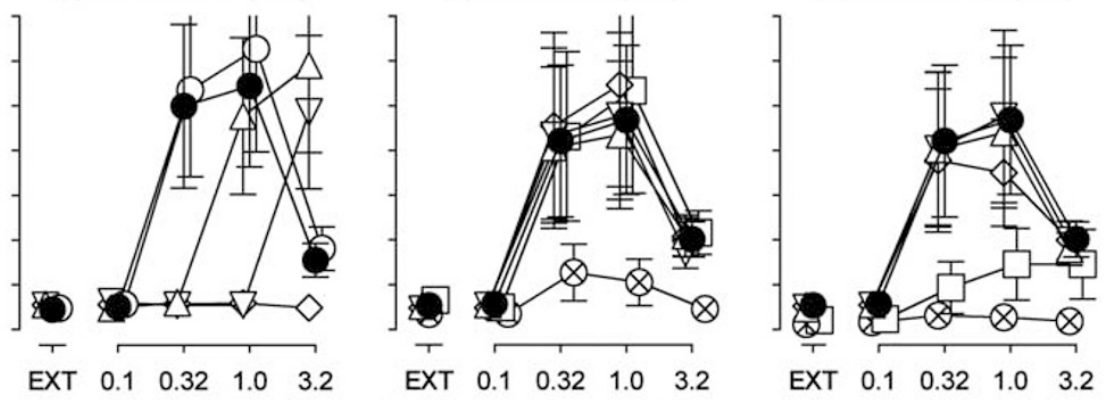

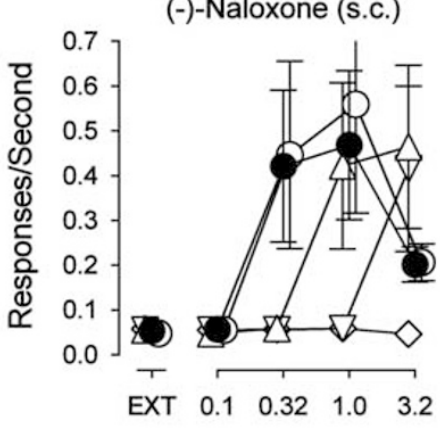

Remifentanil Dose ( $\mu \mathrm{g} / \mathrm{kg} / \mathrm{injection}$, i.v.)

Figure 3 Effects of (+)-naloxone and (+)-naltrexone on self-administration of cocaine or remifentanil in rats trained to self-administer cocaine $(0.032-1.0 \mathrm{mg} / \mathrm{kg} / \mathrm{inj})$. Ordinates: responses per second; abscissae: dose of each substituted drug in $\mathrm{mg} / \mathrm{kg} / \mathrm{inj}$ or component. Each point represents the mean \pm SEM; $(n=6)$. EXT, extinction. All pretreatment drugs were administered s.c. at 5 min before sessions. (a) Substitution of saline for cocaine. Cocaine injections at doses of 0.1 and $0.32 \mathrm{mg} / \mathrm{kg} / \mathrm{inj}$ maintained responding above saline injections. (b) Effects of the opioid antagonists on cocaine self-administration. (c, d) Effects of the TLR4 antagonists on cocaine self-administration. Pretreatments with increasing doses of (+)-naloxone were virtually inactive (c). Pretreatments with increasing doses of (+)-naltrexone produced dose-related decreases in the maximal self-administration of cocaine (d). (e, $f$ ) Effects of the opioid antagonists on opioid self-administration showing the expected dose-dependent rightward shifts in the remifentanil dose-effect curve. (g, h) Effects of the TLR4 antagonists on opioid self-administration.

Subjects trained to discriminate cocaine, $10.0 \mathrm{mg} / \mathrm{kg}$ i.p., vs saline, i.p., injections showed a dose-related increase in the percentage of cocaine-appropriate responses as dose was increased up to the training dose (Figure 5a, top panel, filled circles). Neither saline nor (+)-naloxone, either i.p. or s.c., administered alone produced a maximum level of drugappropriate responses that exceeded $12 \%$ (Figure $5 \mathrm{a}$, top panel, open symbols). The absence of cocaine-like responding was obtained across the range of doses from those having no effect to those that decreased response rates (Figure 5a bottom panel). Neither $(+)$ - nor $(-)$-naloxone pretreatment appreciably altered the discriminative-stimulus effects of cocaine when administered in combination by either i.p. or s.c. routes (Figures $5 \mathrm{~b}$ and $\mathrm{c}$ upper panels).

\section{DISCUSSION}

The present results indicate that in vivo antagonism at TLR4 receptors with the $(+)$-enantiomers of opioid antagonists does not significantly reduce the increased DA levels induced by acute administration of heroin or cocaine in rats. The lack 


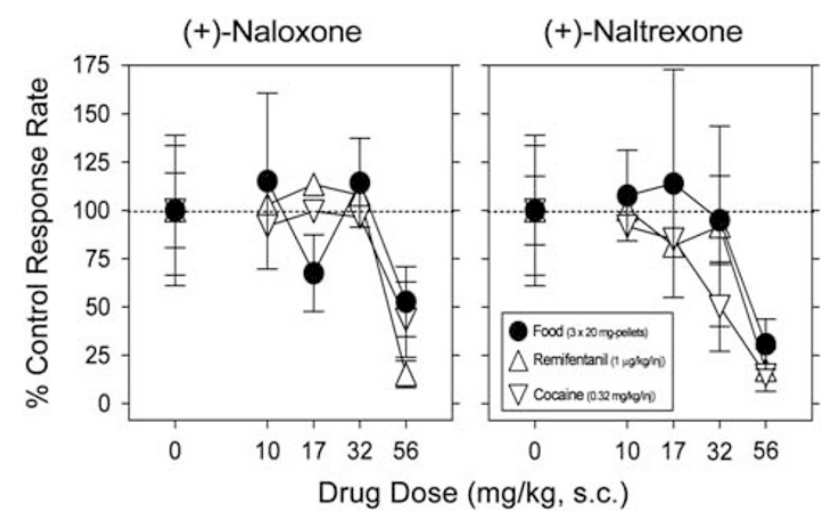

Figure 4 Comparison of effects of pre-session treatments with the TLR4 antagonists on responding maintained by injections of cocaine $(0.32 \mathrm{mg} / \mathrm{kg} /$ inj, open triangles down), remifentanil ( $\mu \mathrm{g} / \mathrm{kg} / \mathrm{inj}$, open triangles up), or food presentation $(3 \times 20 \mathrm{mg}$ pellets, solid circles; fourth component of the session, for each reinforcer). Ordinates: response rates as percentage of control response rates (sessions before drug tests); abscissae: $\mathrm{mg} / \mathrm{kg}$ of test compounds (s.c.), log scale. Each point represents the mean \pm S.E.M. $(n=6)$. All pretreatment drugs were administered s.c. at 5 min before sessions. Behavioral effects of $(+)$-naloxone and $(+)$-naltrexone appeared to be non-specific for drugs of abuse as they were obtained at doses that also decreased comparable behavior maintained by food reinforcement.

of effect was obtained under a variety of experimental conditions including a wide range of $(+)$-naloxone or $(+)$-naltrexone doses as well as different routes of administration. Indeed, in several experiments the effects of pretreatments with the TLR4 antagonists enhanced rather than attenuated cocaine-induced DA increases. Further, although both $(+)$-naloxone and (+)-naltrexone reduced opioid agonist or cocaine self-administration, those reductions were obtained at relatively high doses of the (+)-enantiomers which also decreased comparable foodmaintained responding. These results suggest that the effects of tested (+)-opioids on cocaine or opioid self-administration are owing to a non-specific behavioral disruption.

The present microdialysis results contrast with previous reports in which $(+)$-naloxone or (+)-naltrexone attenuated the increases in nucleus accumbens dopamine produced by morphine or cocaine (Hutchinson et al, 2012; Northcutt et al, 2015). Several procedural differences between those utilized previously and those of the present studies were experimentally addressed in an attempt to reconcile the differences between outcomes. In one experiment the fast onset/offset of dopaminergic effects of i.v. heroin administration were evaluated. Three i.v. heroin doses were administered spaced $30 \mathrm{~min}$ apart. We try to antagonize the dopaminergic effect of heroin with larger doses of TLR4 antagonist compared with those originally used in microdialysis tests in Hutchinson et al (2012). However, doses of the antagonists were in the same range of those administered in Hutchinson et al (2012) and Northcutt et al (2015) to antagonize i.v. self-administration of remifentanil, another $\mu$ opioid receptor agonist, or cocaine. Then, in a different experiment, the effects of the anesthetic used for implanting dialysis probes was examined, as our initial experiments used a ketamine/xylazine combination compared with the isoflurane used in the published reports. However, a lack of effects of $(+)$-naloxone on cocaine-induced stimulation of
DA levels was observed using either anesthetic. Both ketamine and isoflurane have been reported to impact neuro-inflammation, with acute and long-lasting effects (Lockwood et al, 1993; Miyazaki et al, 1997; Wu et al, 2008; Xiang et al, 2014; Xiao et al, 2015; Zhao et al, 2011). Further, changes in glutamate, GABA, and calcium $^{++}$ oscillation signaling have been reported after isoflurane anesthesia (Miyazaki et al, 1997; Xiang et al, 2014; Zhao et al, 2011). Therefore, a difference depending on anesthetic agent was a distinct possibility, though that influence is more likely at $24 \mathrm{~h}$ than several days after surgery, as in the previous experiments (Hutchinson et al, 2012; Northcutt et al, 2015). Nonetheless, we tested subjects in which guide cannulas were surgically implanted $\sim 1$ or 3 weeks before, with microdialysis probes lowered into the NAS through the guides without anesthesia, $24 \mathrm{~h}$ before tests. Neither the effects of cocaine alone nor the absence of (+)-naloxone effects on the DA response to cocaine were altered by the different surgical procedures.

Although the behavioral effects presently reported largely replicate results from previous reports (Hutchinson et al, 2012; Northcutt et al, 2015), the interpretation of the data differs from previous studies in light of results from foodreinforced responding; neither of the $(+)$-enantiomers were substantially more potent in their effects on selfadministration than they were on responding maintained by food reinforcement. Those similar potencies indicate that the decreases in responding produced by $(+)$-naloxone or $(+)$-naltrexone were generalized behavioral disrupting effects of the drugs (likely owing to the administration of large drug doses resulting in non-specific effects), and not a reflection of specific effects on the self-administration of abused drugs.

The highest dose of $(-)$-naltrexone examined in the present study, $32 \mathrm{mg} / \mathrm{kg}$, had no effect on the selfadministration of cocaine, whereas that dose of (+)-naltrexone decreased cocaine self-administration. In contrast, previous reports of TLR4 antagonist effects of the enantiomers have indicated that they are equipotent with regard to TLR4 antagonist effects (Hutchinson et al, 2011; Wang et al, 2016). The differences in potency for decreasing cocainemaintained responding compared to the similar potencies for TLR4 antagonism suggest that the former effects are not due to TLR4 antagonism. The non-selective decreases in response rates produced by the high doses of $(+)$-naloxone and $(+)$-naltrexone may be related to the reported functional blockade of GABA-inhibitory systems previously reported for high doses of (-)-naloxone (Dingledine et al, 1978).

The subjective effects of cocaine were assessed in the present study using a drug-discrimination procedure. Neither (+)-naloxone by s.c. or i.p. routes of administration produced significant alterations of the discriminativestimulus effects of cocaine. As with self-administration, the discriminative-stimulus effects of cocaine are thought to be involved in its abuse liability. Importantly with regard to the issues discussed above about surgical procedures, the absence of (+)-naloxone effects occurred in a procedure free of surgical preparation, but related to the abuse liability of cocaine, further suggesting a lack of TLR4 involvement in the abuse liability of cocaine.

The neuro-inflammation process that has been described after morphine or cocaine administration might be expected to require time and possibly extended exposure to the drugs 
a
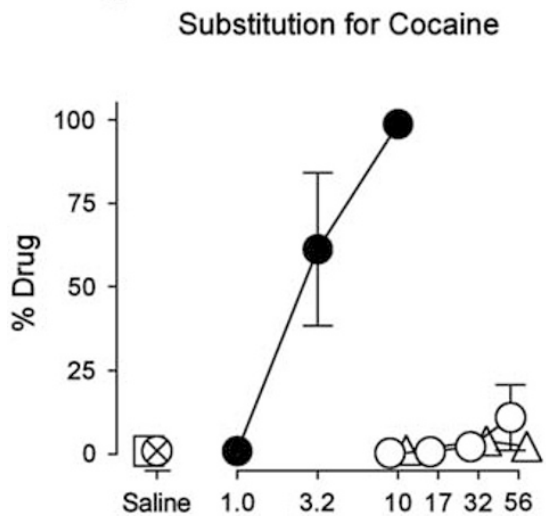

Cocaine (i.p.) $\bigcirc$ (+)-Naloxone (s.c.)

$\otimes$ Saline (i.p.) $\triangle(+$ (+)-Naloxone (i.p.)

Saline (s.c.) b

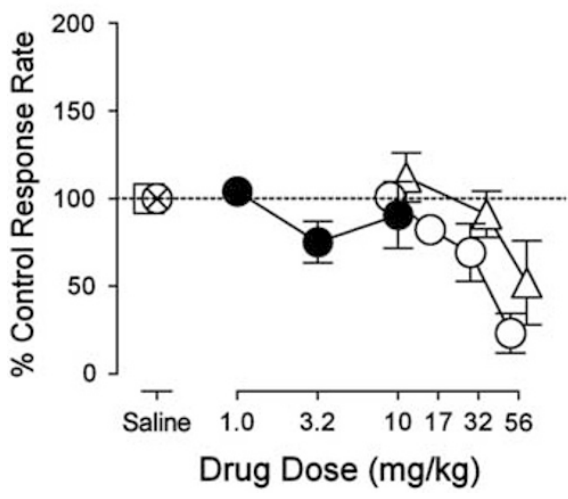

(+)-Naloxone

(s.c.)
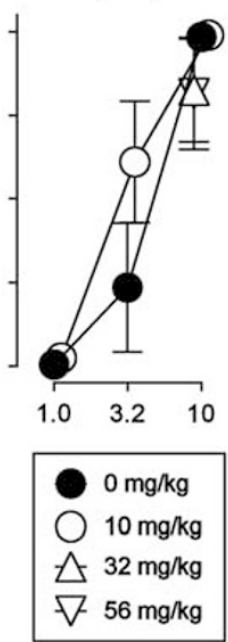

c

(+)-Naloxone

(i.p.)
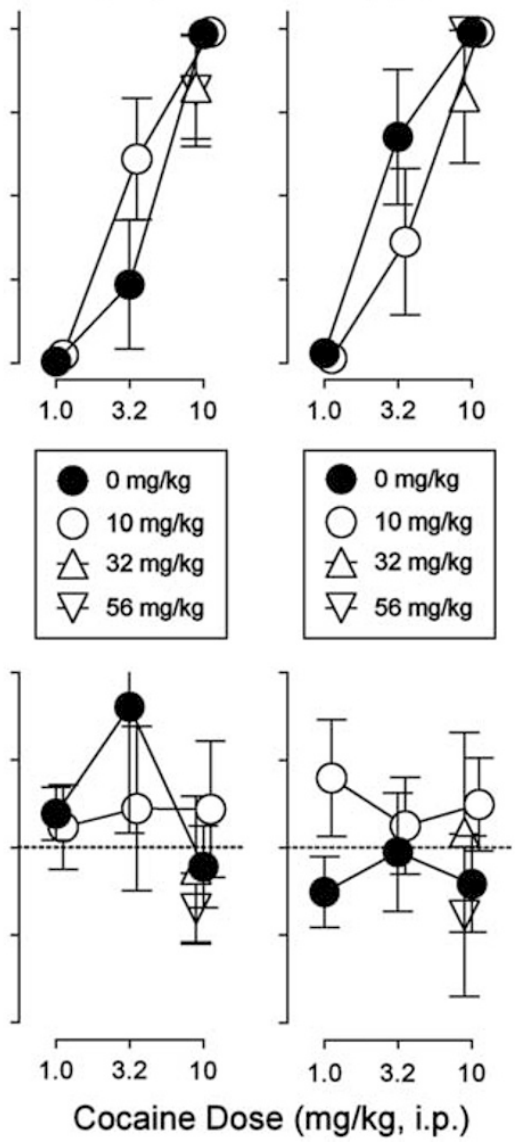

Figure 5 Effects of (+)-naltrexone on the discriminative-stimulus effects of cocaine. Abscissae: drug dose in mg/kg (log scale). Ordinates: upper panels, percentage of responses on the cocaine-appropriate lever; lower panels, percentage of response rate after saline administration. Each point represents the mean \pm SEM $(n=5)$. All drugs were administered i.p. or s.c. at 5 min before sessions. (a, top) Substitution of saline or (+)-naloxone for cocaine. No dose of $(+)$-naloxone produced cocaine-like discriminative-stimulus effects regardless of the route of administration (i.p. or s.c.). (a, bottom) As already shown for the self-administration results, high doses of $(+)$-naloxone decreased response rates. $(b, c)$ No dose of $(+)$-naloxone administered in combination with cocaine blocked the discriminative-stimulus effects of cocaine, regardless of the route of (+)-naloxone (i.p. or s.c.) administration. When combined with cocaine, the decreases in response rates produced by $(+)$-naloxone were attenuated compared to its effects alone.

(Campbell et al, 2013; Taylor et al, 2016; Zhang et al, 2011). Extended exposure was not a part of the neurochemical studies reported here, nor those reported previously. However, Theberge et al (2013) reported that chronic delivery of (+)-naltrexone via minipumps during the withdrawal phase decreased "incubated cue-induced heroin seeking" in rats. This effect was not replicated with acute injections of (+)-naltrexone, which had no effect on methamphetamine seeking. Further, that study did not compare the effects of treatments on comparable responding maintained by a non-drug reinforcer to assess the specificity of the effect (Theberge et al, 2013).

If extended exposure is integral to the neuro-inflammatory response to drugs of abuse, it seems unlikely that TLR4 antagonism would produce a complete blunting of acute dopaminergic stimulant effects of cocaine or morphine as reported previously (Hutchinson et al, 2012; Northcutt et al, 2015). Moreover, a pathway for TLR4 antagonism of (1) cocaine actions mediated by neuronal membrane DAT in dopaminergic terminal areas, such as NAS, and (2) opioid attenuation of inhibitory control of VTA GABA neurons on DA neuronal firing producing elevations of DA in NAS provided by glia remains to be identified.

Recently, a morphine-induced neuro-immune mechanism independent of TLR4 has been demonstrated in morphinedependent animals (Ferrini et al, 2013). Through this mechanism, there is a loss of chloride ions resulting from microglia-derived BDNF reducing expression and function of potassium-chloride cotransporter 2. Such dysregulation in VTA could interfere with reinforcing or other behavioral effects of abused drugs in morphine-exposed animals, suggesting a potential new target for opioid abuse (Taylor et al, 2016; 2015).

In conclusion, the previously described in vivo neurochemical findings reported by Hutchinson et al (2012) and Northcutt et al (2015) were not reproduced in the present study. Various doses were utilized as well as changes in methods to closely approximate those used in the previous 
studies without a better approximation of the previous neurochemical results. Alternatively, similar behavioral results were obtained with both TLR4 antagonists decreasing either cocaine or opioid agonist (remifentanil) selfadministration. However, those decreases appeared to be non-specific as they were obtained at doses that also decreased comparable behavior maintained by food reinforcement. Taken together the present results do not suggest a selective involvement of TLR4 signaling in NAS DA neurotransmission, nor in cocaine or opioid reinforcement.

\section{FUNDING AND DISCLOSURE}

The authors declare no conflict of interest.

\section{ACKNOWLEDGMENTS}

The animals in the present study were maintained in an AAALAC International accredited facility in accordance with NIH Policy Manual 3040-2, Animal Care and Use in the Intramural Program (releasedon 1 November 1999). Care of the subjects was in accordance with the guidelines of the National Institutes of Health and the National Institute on Drug Abuse Intramural Research Program Animal Care and Use Program, which is fully accredited by AAALAC International. We thank Dr Kenner Rice for providing us the (+)-enantiomers of the opioid antagonists. We also thank Dr Amy Newman for early discussion about the topic of this manuscript. The present study has been funded by the Medication Development Program, NIDA-IRP, and by NIDA-IRP, NIH/DHHS.

\section{REFERENCES}

Bachtell R, Hutchinson MR, Wang X, Rice KC, Maier SF, Watkins LR (2015). Targeting the Toll of drug abuse: the translational potential of Toll-like receptor 4. CNS Neurol Disord Drug Targets 14: 692-699.

Campbell LA, Avdoshina V, Rozzi S, Mocchetti I (2013). CCL5 and cytokine expression in the rat brain: differential modulation by chronic morphine and morphine withdrawal. Brain Behav Immun 34: 130-140.

Di Chiara G, Acquas E, Tanda G, Cadoni C (1993). Drugs of abuse: biochemical surrogates of specific aspects of natural reward? Biochem Soc Symp 59: 65-81.

Di Chiara G, North RA (1992). Neurobiology of opiate abuse. Trends Pharmacol Sci 13: 185-193.

Di Chiara G, Tanda G, Bassareo V, Pontieri F, Acquas E, Fenu S et al (1999). Drug addiction as a disorder of associative learning. Role of nucleus accumbens shell/extended amygdala dopamine. Ann N Y Acad Sci 877: 461-485.

Di Chiara G, Tanda G, Cadoni C, Acquas E, Bassareo V, Carboni E (1998). Homologies and differences in the action of drugs of abuse and a conventional reinforcer (food) on dopamine transmission: an interpretative framework of the mechanism of drug dependence. Adv Pharmacol 42: 983-987.

Di Chiara G, Tanda G, Carboni E (1996). Estimation of in vivo neurotransmitter release by brain microdialysis: the issue of validity. Behav Pharmacol 7: 640-657.

Dingledine R, Iversen LL, Breuker E (1978). Naloxone as a GABA antagonist: evidence from iontophoretic, receptor binding and convulsant studies. Eur J Pharmacol 47: 19-27.

Ferrini F, Trang T, Mattioli TA, Laffray S, Del'Guidice T, Lorenzo LE et al (2013). Morphine hyperalgesia gated through microglia-mediated disruption of neuronal $\mathrm{Cl}(-)$ homeostasis. Nat Neurosci 16: 183-192.

Fukagawa H, Koyama T, Kakuyama M, Fukuda K (2013). Microglial activation involved in morphine tolerance is not mediated by toll-like receptor 4. J Anesth 27: 93-97.

Garces-Ramirez L, Green JL, Hiranita T, Kopajtic TA, Mereu M, Thomas AM et al (2011). Sigma receptor agonists: receptor binding and effects on mesolimbic dopamine neurotransmission assessed by microdialysis. Biol Psychiatry 69: 208-217.

Hutchinson MR, Lewis SS, Coats BD, Rezvani N, Zhang Y, Wieseler JL et al (2010). Possible involvement of toll-like receptor $4 /$ myeloid differentiation factor-2 activity of opioid inactive isomers causes spinal proinflammation and related behavioral consequences. Neuroscience 167: 880-893.

Hutchinson MR, Northcutt AL, Hiranita T, Wang X, Lewis SS, Thomas J et al (2012). Opioid activation of toll-like receptor 4 contributes to drug reinforcement. J Neurosci 32: 11187-11200.

Hutchinson MR, Shavit Y, Grace PM, Rice KC, Maier SF, Watkins LR (2011). Exploring the neuroimmunopharmacology of opioids: an integrative review of mechanisms of central immune signaling and their implications for opioid analgesia. Pharmacol Rev 63: 772-810.

Hutchinson MR, Watkins LR (2014). Why is neuroimmunopharmacology crucial for the future of addiction research? Neuropharmacology 76 Pt B: 218-227.

Hutchinson MR, Zhang Y, Brown K, Coats BD, Shridhar M, Sholar PW et al (2008). Non-stereoselective reversal of neuropathic pain by naloxone and naltrexone: involvement of toll-like receptor 4 (TLR4). Eur J Neurosci 28: 20-29.

Iijima I, Minamikawa J, Jacobson AE, Brossi A, Rice KC (1978). Studies in the $(+)$-morphinan series. 5. Synthesis and biological properties of (+)-naloxone. J Med Chem 21: 398-400.

Johnson SW, North RA (1992). Opioids excite dopamine neurons by hyperpolarization of local interneurons. J Neurosci 12: 483-488.

Koob GF, Volkow ND (2010). Neurocircuitry of addiction. Neuropsychopharmacology 35: 217-238.

Lee CC, Avalos AM, Ploegh HL (2012). Accessory molecules for Toll-like receptors and their function. Nat Rev Immunol 12: 168-179.

Lewis SS, Loram LC, Hutchinson MR, Li CM, Zhang Y, Maier SF et al (2012). (+)-naloxone, an opioid-inactive toll-like receptor 4 signaling inhibitor, reverses multiple models of chronic neuropathic pain in rats. J Pain 13: 498-506.

Lockwood LL, Silbert LH, Laudenslager ML, Watkins LR, Maier SF (1993). Anesthesia-induced modulation of in vivo antibody levels: a study of pentobarbital, chloral hydrate, methoxyflurane, halothane, and ketamine/xylazine. Anesth Analg 77: 769-774.

Mattioli TA, Leduc-Pessah H, Skelhorne-Gross G, Nicol CJ, Milne B, Trang T et al (2014). Toll-like receptor 4 mutant and null mice retain morphine-induced tolerance, hyperalgesia, and physical dependence. PLoS One 9: e97361.

Miyazaki H, Nakamura Y, Arai T, Kataoka K (1997). Increase of glutamate uptake in astrocytes: a possible mechanism of action of volatile anesthetics. Anesthesiology 86: 1359-1366.

Northcutt AL, Hutchinson MR, Wang X, Baratta MV, Hiranita T, Cochran TA et al (2015). DAT isn't all that: cocaine reward and reinforcement require Toll-like receptor 4 signaling. Mol Psychiatry 20: 1525-1537.

Paxinos G, Watson C (1998). The Rat Brain in Stereotaxic CoordinatesIV edn.Academic Press: Sydney, Australia.

Pontieri FE, Tanda G, Di Chiara G (1995). Intravenous cocaine, morphine, and amphetamine preferentially increase extracellular dopamine in the 'shell' as compared with the 'core' of the rat nucleus accumbens. Proc Natl Acad Sci USA 92: 12304-12308.

Pontieri FE, Tanda G, Orzi F, Di Chiara G (1996). Effects of nicotine on the nucleus accumbens and similarity to those of addictive drugs. Nature 382: 255-257. 
Roy S, Cain KJ, Chapin RB, Charboneau RG, Barke RA (1998). Morphine modulates NF kappa B activation in macrophages. Biochem Biophys Res Commun 245: 392-396.

Skolnick P, Davis H, Arnelle D, Deaver D (2014). Translational potential of naloxone and naltrexone as TLR4 antagonists. Trends Pharmacol Sci 35: 431-432.

Stevens CW, Aravind S, Das S, Davis RL (2013). Pharmacological characterization of LPS and opioid interactions at the toll-like receptor 4. Br J Pharmacol 168: 1421-1429.

Tanda G, Ebbs A, Newman AH, Katz JL (2005). Effects of 4'-chloro3 alpha-(diphenylmethoxy)-tropane on mesostriatal, mesocorti$\mathrm{cal}$, and mesolimbic dopamine transmission: comparison with effects of cocaine. J Pharmacol Exp Ther 313: 613-620.

Tanda G, Ebbs AL, Kopajtic TA, Elias LM, Campbell BL, Newman AH et al (2007). Effects of muscarinic M1 receptor blockade on cocaine-induced elevations of brain dopamine levels and locomotor behavior in rats. J Pharmacol Exp Ther 321: 334-344.

Tanda G, Kopajtic TA, Katz JL (2008). Cocaine-like neurochemical effects of antihistaminic medications. J Neurochem 106: 147-157.

Tanda G, Newman AH, Ebbs AL, Tronci V, Green JL, Tallarida RJ et al (2009). Combinations of cocaine with other dopamine uptake inhibitors: assessment of additivity. J Pharmacol Exp Ther 330: 802-809.

Tanda G, Pontieri FE, Di Chiara G (1997a). Cannabinoid and heroin activation of mesolimbic dopamine transmission by a common mul opioid receptor mechanism. Science 276: 2048-2050.

Tanda G, Pontieri FE, Frau R, Di Chiara G (1997b). Contribution of blockade of the noradrenaline carrier to the increase of extracellular dopamine in the rat prefrontal cortex by amphetamine and cocaine. Eur J Neurosci 9: 2077-2085.

Taylor AM, Castonguay A, Ghogha A, Vayssiere P, Pradhan AA, Xue $L$ et al (2016). Neuroimmune regulation of GABAergic neurons within the ventral tegmental area during withdrawal from chronic morphine. Neuropsychopharmacology 41: 949-959.
Taylor AM, Castonguay A, Taylor AJ, Murphy NP, Ghogha A, Cook C et al (2015). Microglia disrupt mesolimbic reward circuitry in chronic pain. J Neurosci 35: 8442-8450.

Theberge FR, Li X, Kambhampati S, Pickens CL St, Laurent R, Bossert JM et al (2013). Effect of chronic delivery of the Toll-like receptor 4 antagonist (+)-naltrexone on incubation of heroin craving. Biol Psychiatry 73: 729-737.

Wang X, Zhang Y, Peng Y, Hutchinson MR, Rice KC, Yin H et al (2016). Pharmacological characterization of the opioid inactive isomers (+)-naltrexone and (+)-naloxone as antagonists of tolllike receptor 4. Br J Pharmacol 173: 856-869.

Watkins LR, Hutchinson MR, Rice KC, Maier SF (2009). The 'toll' of opioid-induced glial activation: improving the clinical efficacy of opioids by targeting glia. Trends Pharmacol Sci 30: 581-591.

Wise RA (1998). Drug-activation of brain reward pathways. Drug Alcohol Depend 51: 13-22.

Wu GJ, Chen TL, Ueng YF, Chen RM (2008). Ketamine inhibits tumor necrosis factor-alpha and interleukin-6 gene expressions in lipopolysaccharide-stimulated macrophages through suppression of toll-like receptor 4-mediated c-Jun N-terminal kinase phosphorylation and activator protein-1 activation. Toxicol Appl Pharmacol 228: 105-113.

Xiang HF, Cao DH, Yang YQ, Wang HQ, Zhu LJ, Ruan BH et al (2014). Isoflurane protects against injury caused by deprivation of oxygen and glucose in microglia through regulation of the Toll-like receptor 4 pathway. J Mol Neurosci 54: 664-670.

Xiao Z, Ren P, Chao Y, Wang Q, Kuai J, Lv M et al (2015). Protective role of isoflurane pretreatment in rats with focal cerebral ischemia and the underlying molecular mechanism. Mol Med Rep 12: 675-683.

Zhang Y, Li H, Li Y, Sun X, Zhu M, Hanley G et al (2011). Essential role of toll-like receptor 2 in morphine-induced microglia activation in mice. Neurosci Lett 489: 43-47.

Zhao YL, Xiang Q, Shi QY, Li SY, Tan L, Wang JT et al (2011). GABAergic excitotoxicity injury of the immature hippocampal pyramidal neurons' exposure to isoflurane. Anesth Analg 113: $1152-1160$.

Supplementary Information accompanies the paper on the Neuropsychopharmacology website (http://www.nature.com/npp) 